This item was submitted to Loughborough's Research Repository by the author.

Items in Figshare are protected by copyright, with all rights reserved, unless otherwise indicated.

\title{
Optimising classification of proximal arm strength impairment in wheelchair rugby: a proof of concept study
}

PLEASE CITE THE PUBLISHED VERSION

https://doi.org/10.1080/02640414.2021.1883291

\section{PUBLISHER}

Taylor \& Francis

\section{VERSION}

AM (Accepted Manuscript)

\section{PUBLISHER STATEMENT}

This is an Accepted Manuscript of an article published by Taylor \& Francis in Journal of Sports Sciences on 4 Feb 2021, available online: http://www.tandfonline.com/10.1080/02640414.2021.1883291.

\section{LICENCE}

CC BY-NC-ND 4.0

\section{REPOSITORY RECORD}

Mason, Barry, Viola Altmann-Van-Der-Donk, Michael Hutchinson, Nicola Petrone, Francesco Bettella, and Vicky Goosey-Tolfrey. 2021. "Optimising Classification of Proximal Arm Strength Impairment in Wheelchair Rugby: A Proof of Concept Study”. Loughborough University. https://hdl.handle.net/2134/13650347.v1. 
1 Optimising classification of proximal arm strength impairment in wheelchair rugby: a

2 proof of concept study

3

4 Original investigation

5

6 Barry S. Mason, ${ }^{1}$ Viola C. Altmann, ${ }^{1,2}$ Michael J. Hutchinson, ${ }^{1}$ Nicola, Petrone, ${ }^{3}$ Francesco

7 Bettella, ${ }^{3}$ Victoria L. Goosey-Tolfrey. ${ }^{1}$

8

$9{ }^{1}$ Peter Harrison Centre for Disability Sport, School of Sport, Exercise \& Health Sciences, 10 Loughborough University, UK.

$11{ }^{2}$ Rehabilitation Medical Center Groot Klimmendaal, the Netherlands.

$12{ }^{3}$ Department of Industrial Engineering, University of Padova, Italy.

14 Corresponding author:

15 Dr Barry S. Mason

16 Peter Harrison Centre for Disability Sport, School of Sport, Exercise \& Health Sciences,

17 Loughborough University, UK.

18 Email - $\underline{\text { b.mason@ }, 1 \text { lboro.ac.uk }}$

19 Phone - +44 (0) 1509226387

22 Abstract word count: 200 words

23 Manuscript word count: 3666 words

24 Tables: 4

25 Figures: 2

26 Supplementary material: 1 
Abstract

This study examined the relationship between proximal arm strength and mobility performance in wheelchair rugby (WR) athletes and examined whether a valid structure for classifying arm strength impairment could be determined. Fifty-seven trained WR athletes with strength impaired arms and no trunk function performed six upper body isometric strength tests and three $10 \mathrm{~m}$ sprints in their rugby wheelchair. All strength measures correlated with $2 \mathrm{~m}$ and 10 m sprint times $(r \geq-0.43 ; \mathrm{p} \leq 0.0005)$ and were entered into k-means cluster analyses with 4clusters (to mirror the current International Wheelchair Rugby Federation [IWRF] system) and 3-clusters. The 3-cluster structure provided a more valid structure than both the 4-cluster and existing IWRF system, as evidenced by clearer differences in strength (Effect sizes $[$ ES] $\geq 1.0$ ) and performance $(E S \geq 1.1)$ between adjacent clusters and stronger mean silhouette coefficient (0.64). Subsequently, the 3-cluster structure for classifying proximal arm strength impairment would result in less overlap between athletes from adjacent classes and reduce the likelihood of athletes being disadvantaged due to their impairment. This study demonstrated that the current battery of isometric strength tests and cluster analyses could facilitate the evidencebased development of classifying proximal arm strength impairment in WR.

Keywords: Paralympics, cluster analysis, spinal cord injury, isometric, sports performance, disability sport 
Wheelchair rugby (WR) is a Paralympic team sport initially developed for athletes with a strength impairment resulting from a spinal cord injury (SCI). However, athletes with other health conditions and physical impairment types are now also eligible to compete (International Wheelchair Rugby Federation [IWRF], 2015). As with most Paralympic sports, WR adopts a classification system, designed to minimise the impact of impairment type and severity on the outcomes of competition (Tweedy, 2002). Athletes are classified into one of seven classes ranging from 0.5 (most impaired) to 3.5 (least impaired) at 0.5 intervals, depending on the severity of their trunk and upper extremity impairment. Using manual muscle testing, the trunk is scored between 0 to 1.5 and both upper extremities are scored between 0.5 to 3.5 . Scores for both upper extremities are averaged and added to the trunk score to give an athlete's overall classification (IWRF, 2018).

In recent years the International Paralympic Committee (IPC) has published a position stand (Tweedy and Vanlandewijck, 2011) and a classification code (IPC, 2015), which mandated the development of evidence-based systems of classification in all Paralympic sports, whereby class allocation should be based on empirical evidence rather than subjective, expert opinion. Subsequently, scientific research has become a prominent feature in the development of evidence-based systems (Tweedy et al., 2016). Within WR, substantial research has been conducted to establish and validate the four trunk scores for athletes of all eligible impairment types (Altmann et al., 2016, 2017, 2018). Yet, upper extremity impairment testing is limited to strength impairment only and the scores allocated are not supported by research and as such remain expert opinion-based, rather than evidence-based.

Upper extremity strength impairment can be classed as either proximal or distal weakness in WR athletes depending on the level of the spinal lesion and the resulting muscles 
innervated. This is reflected in the seven scores current used for classifying upper extremity impairment in WR. The first three scores ( 0.5 to 1.5$)$ describe athletes with both proximal (shoulders and elbows) and distal (wrists and hands) upper extremity impairment. Whereas athletes with a distally located impairment only are allocated to one of the four (2.0 to 3.5) remaining scores (IWRF, 2015). Due to the nature of the SCI, athletes with proximal impairments typically have no trunk function (trunk score 0 ) and as a result, often occupy defensive roles on court. As such, ball handling is not a big part of their responsibilities, whereas linear wheelchair mobility performance is. Alternatively, athletes with only a distal impairment, who may or may not have some trunk function, occupy offensive roles, where both ball handling, linear and multidirectional mobility are all vital.

According to the IPC position stand, tests of impairment must firstly be specific to the impairment of interest and secondly, related to areas of performance specific to the impairment (Tweedy and Vanlandewijck, 2011). Tests should also be objective, reliable, ratio scaled and valid (Tweedy and Vanlandewijck, 2011). Unfortunately, no such tests exist to quantify either distal impairments to the upper extremities or aspects of ball handling performance specific to WR. However, a series of isometric strength tests that were objective, reliable, ratio scaled and valid for the assessment of proximal upper extremity strength impairment in WR players have recently been developed (Mason et al., 2019). Athletes with proximal arm strength impairment and no trunk function also account for $41 \%$ of registered WR athletes worldwide. So not only are they primed for evidence-based classification research, they are clearly a priority group within WR too and hence are the focus of the current investigation.

The next step when working towards evidence-based classification is to establish the relationships between tests of impairment and performance (Tweedy and Vanlandewijck, 2011). Following this step, recent investigations have employed statistical machine learning techniques such as cluster analyses to establish whether valid classification structures for class 
97 allocation can be achieved (Connick et al., 2018a). However, this has only been observed in a small number of Paralympic sports and impairment types (Altmann et al., 2018; Connick et al., 2018b; Hogarth et al., 2018). Subsequently the aim of the current study was to firstly explore the relationship between proximal arm strength impairment and linear mobility performance in highly trained WR athletes using isometric strength tests. The second aim was to explore whether a valid classification structure could be produced via cluster analyses of the strength data and to compare this structure to the current IWRF system for classifying proximal arm strength impairment. The current study is a proof of concept and the results will serve as an important step towards evidence-based classification for strength impaired athletes in WR.

\title{
Methods
}

\section{$\underline{\text { Participants }}$}

Fifty-seven WR athletes participated in the study. All athletes had a SCI with a 0-trunk score and varying severities of arm impairment (0.5 to 1.5$)$, with athletes with no proximal muscle weakness (2.0), also included for comparison (Table 1). Ethical approval for the study was granted by the University's local ethical advisory committee. Athletes provided their written informed consent prior to the commencement of the study. Data was collected at a variety of international WR competitions and training camps throughout 2018-2019 and included athletes from North America, Europe, Asia and Oceania, where the major WR nations exist.

\section{$\underline{\text { Design }}$}

\author{
***INSERT TABLE 1 HERE***
}


Testing was conducted using a portable, customised strength rig developed to measure maximal isometric strength in WR athletes. The rig, which consisted of a weighted platform with aluminium frames, incorporated an S-type load cell $(500 \mathrm{~kg})$ that could be attached to athletes and their wheelchairs in a variety of positions. Force data was collected from the load cell via a MuscleLab acquisition unit sampling at $200 \mathrm{~Hz}$ (ErgoTest, Porsgrunn, Norway).

Six isometric strength tests were developed by the research team to determine proximal arm strength impairment during actions specific to WR. Four of the tests were singe-joint actions, which explored maximal isometric strength during flexion and extension of the shoulder and elbow, which have been validated previously (Mason et al., 2019). Two further multi-joint tests were also incorporated to assess athlete's capacity to isometrically 'push' and 'pull' their wheelchair (Supplementary Figure 1). Athletes performed all testing in their own rugby wheelchairs with the gloves, tape and strapping that they use for competition. Although subtle differences in wheelchair configuration existed, all athletes used a combination of abdominal and waist straps, which was important for standardising stability. For the singlejoint actions, the main wheels were removed so that the equipment did not inhibit the actions. Athletes were instructed to keep a $90^{\circ}$ flexed elbow, verified using a goniometer, and their upper arm in a neutral position by their side, during all single-joint actions. For shoulder flexion and extension, a Velcro cuff was attached horizontally around the most distal part of the humerus, whilst the elbow was flexed, which was secured to the load cell by a cable adjusted to be parallel to the ground. For elbow flexion and extension, the centre of the cuff was positioned in line with the centre of the wrist joint (midpoint between the ulnar and radial styloid) and the participant positioned to ensure they performed the movement in direct line with the load cell. Athletes were required to relax their arm into the load cell prior to the elbow extension test to account for gravity and interindividual differences in arm mass. Once a stable reading was acquired, the force trace was zeroed before the trial commenced. For the multi- 
joint movements, players main wheels were attached and positioned on two pieces of high friction rubber to prevent slippage during the tasks. For the 'push' test the load cell was attached to the bar behind the backrest of athletes' wheelchairs and for the 'pull' test, this was attached around the pick bar on the front of the wheelchair. During both these tests the cable connecting the wheelchairs to the load cell was parallel to the ground, verified by a spirit level. Athletes were instructed to push/pull at the position on the wheels at which they thought they could produce the most force. Practice trials, which were not recorded, were permitted for athletes to establish their perceived strongest position.

Following practice trials at $\sim 50 \%$ to $75 \%$ of maximum effort, athletes performed $3 \times 5$ sec trials for each test, with 5-sec rest in between (Mason et al., 2019). Athletes were instructed to gradually build towards peak force within the first 2 seconds and then maintain maximal force production for the remaining 3 seconds (Connick et al., 2018b). Verbal encouragement was provided throughout to facilitate maximal effort. The order for each strength test was randomised using simple randomisation for each participant. For the single joint tests, a further simple randomisation was applied to determine the order for left and right sides.

Athletes were also required to perform $3 \times 10 \mathrm{~m}$ sprints in their customised rugby wheelchairs. Wireless timing gates (Brower Timing Systems, Utah, USA) were positioned at $2 \mathrm{~m}$ and $10 \mathrm{~m}$ to assess acceleration and sprinting performance, both of which have been identified as key indicators of performance to WR athletes (Mason et al., 2010). Athletes started from a stationary position and were instructed to sprint as fast as they could all the way through the $10 \mathrm{~m}$ line. Rest between trials was permitted and was controlled by athletes who indicated when they were ready to perform their subsequent trial.

\section{$\underline{\text { Data analysis }}$}


Strength data was analysed using MuscleLab professional software (version 19.0). Based on previous guidelines, the area of the force trace where the force had plateaued and displayed the lowest standard deviation over a rolling 1-2 second window was used for analysis (Connick et al., 2018b; Mason et al., 2019). The mean value over this window was defined as the peak isometric force, with the highest value across all three trials included for further analysis. Strength data from the single-joint tests was described as the dominant (D) and non-dominant (ND) side, determined by the side with the highest force value. For the performance tests, only the fastest $2 \mathrm{~m}$ and $10 \mathrm{~m}$ times for each athlete were included for further analysis.

\section{$\underline{\text { Statistical analysis. }}$}

All statistical analyses were performed using the Statistical Package for Social Sciences (SPSS Version 24.0, IBM, New York, USA). Strength and performance measures were checked for normality using Shapiro-Wilk tests. Pearson and Spearman correlation coefficients determined the strength of association between parametric and non-parametric measures of isometric strength and performance respectively. Coefficients were described as negligible $(<0.30)$, low (0.30 to 0.50$)$, moderate $(0.50$ to 0.70$)$ and high $(>0.70)$ according to previous guidelines (Hinkle et al., 2003).

Significantly correlated strength measures were entered into a k-means cluster analysis, which partitions data observations into non-overlapping subgroups (clusters) based on their proximity to the mean of each cluster. The squared sum of within-cluster distances to the centroid of each cluster was calculated and plotted against the cluster number. Using the elbow method (Thorndike, 1953), the inflection point in the curve was used to identify the optimal number of clusters entered into the k-means analysis. Cluster membership and the resulting distance from cluster centroids were determined for each case. The mean intra-cluster distance 
in relation to the mean of the adjacent cluster was then used to calculate the mean silhouette coefficients (Rousseeuw, 1987). Mean silhouette coefficients quantify the overall strength of the class structures identified and were categorised as having 'no substantial structure' $(\leq 0.25)$, 'weak structure' ( 0.25 to 0.50$)$, 'reasonable structure' $(0.51$ to 0.70$)$ or 'strong structure' $(\geq$ 0.71) (Kaufman and Rousseeuw, 2005).

Cohen's effect sizes (ES) and 95\% confidence intervals $(95 \% \mathrm{CI})$ explored the magnitude of strength and performance differences between adjacent classes to further validate interclass structure. ES were classed as 'trivial' $(<0.2)$, small, $(0.2$ to 0.6$)$, moderate $(0.6$ to 1.2), large (1.2 to 2.0) and very large (> 2.0) (Batterham and Hopkins, 2006). Coefficients of variation $(\% \mathrm{CV})$ were reported to demonstrate intraclass variation in strength and performance for existing classes and resulting clusters.

\section{Results}

Significant correlations were identified between all measures of isometric strength and performance and ranged from -0.43 to -0.77 for $2 \mathrm{~m}$ times and -0.55 to -0.82 for $10 \mathrm{~m}$ times (Table 2). All measures of isometric strength were included in the cluster analyses. However, since females possess significantly less strength than males during such tests (Mason et al., 2019) and only 4 were recruited, the female participants were excluded from the cluster analyses. Subsequently, 53 male athletes were included for the cluster analyses. 

the current dataset. Subsequently, k-means cluster analysis was performed using both a 4cluster and 3-cluster structure. Table 3 illustrates the isometric strength scores according to the existing IWRF classes and the alternative 4- and 3-cluster structures produced by the cluster analyses. The mean silhouette coefficient for the 4-cluster structure was 0.40 and was 0.64 for the 3-cluster structure. for the current IWRF system (Figure 1a), but the lower 95\% CI of 23/30 measures were trivial (lowest $95 \% \mathrm{CI} \geq-0.7)$. Moderate $(\mathrm{ES} \geq 0.6)$ to very large differences in strength existed between adjacent clusters in the 4-cluster structure (Figure 1b), with lower 95\% CI spanning into trivial differences (10/30) for fewer measures (lowest 95\% CI $\geq-0.6$ ). The 3-cluster structure revealed moderate $(\mathrm{ES} \geq 1.0$ ) to very large strength differences between adjacent clusters (Figure 1c), with no lower 95\% CI spanning into trivial difference (lowest 95\% CI $\geq$ 0.4). Intraclass variability (\% CV) in strength measures was similar within the proposed 4 - and 3-cluster structures compared to the existing IWRF classes (Table 3).

Moderate differences in performance were identified between adjacent classes in the current $(\mathrm{ES} \geq 0.8), 4$-cluster $(\mathrm{ES} \geq 1.1)$ and 3-cluster $(\mathrm{ES} \geq 1.1)$ structures. However, the lower limits of the $95 \%$ CI for these differences were higher for the 3-cluster structure $(\geq 0.4)$, compared the 4-cluster $(\geq 0.0)$ and existing IWRF structure $(\geq-0.2)$. Intraclass variability $(\%$ 

according to athletes' existing IWRF classification. The 4-cluster structure resulted in $21 / 53$ (40\%) athletes being placed in a different cluster to their existing class. Eight 0.5 athletes moved up into cluster 2, two 1.0 athletes moved down into cluster 1, two 1.5 athletes moved down into cluster 2 and seven 2.0 athletes moved down to cluster 3. Two 2.0 athletes moved down two classes into cluster 2. The 3-cluster structure has the effect of reducing four classes into three clusters. Outside of this change, the 3 -cluster structure resulted in $10 / 53(19 \%)$ athletes being placed in a different cluster to their current classification. Two 0.5 athletes moved up to cluster 2 , three 1.0 athletes moved down to cluster 1 , two 1.5 athletes moved up to cluster 3, with two 2.0 athletes moved down to cluster 2 .

\section{Discussion}

The current study demonstrated that a series of single- and multi-joint isometric tests developed to assess proximal arm strength impairment were all significantly correlated to mobility performance specific to WR. Results indicated that the current system for assessing proximal arm strength impairment in WR athletes was reasonably valid, yet cluster analyses revealed that validity could be further optimised using a 3-cluster structure. These findings demonstrate that isometric tests of proximal arm strength impairment can be used for classification purposes 
and contribute towards the development of evidence-based systems of classification within WR.

\section{Relationship between isometric arm strength and performance}

To be considered for classification purposes, tests of impairment must be objective, ratioscaled, specific to the impairment of interest, valid, reliable, resistant to training and parsimonious (Tweedy and Vanlandewijck, 2011; Beckman et al., 2017). These objectives had largely been achieved in a previous study exploring the validity and reliability of the singlejoint isometric strength tests in an able-bodied population (Mason et al., 2019). However, to determine whether the tests are parsimonious, relationships to performance need to be identified for each test of impairment (Tweedy and Vanlandewijck, 2011). The current study revealed that all tests of proximal arm strength impairment were significantly correlated to performance specific to WR and were stronger for $10 \mathrm{~m}$ times (moderate to high) than $2 \mathrm{~m}$ times (low to high), which is in line with previous observations (Altmann et al., 2017). Stronger relationships to performance were also identified for shoulder flexion and elbow extension compared to other strength measures, which was to be expected based on the findings of a previous electromyographical exploration of wheelchair propulsion (Mulroy et al., 1996). Subsequently the current battery of tests evaluated strength impairment relevant to performance in WR.

\section{Validity of the structures for classifying proximal arm strength impairment}

The second key objective of the current study was to determine whether a valid classification structure could be derived from cluster analyses of the strength measures and to compare these to the current IWRF system. The findings revealed that the existing system used by the IWRF 
to classify proximal arm strength impairments was a reasonably valid system. Small to very

287 large differences in strength and moderate to large differences in performance existed between adjacent classes in the current system. That said the lower 95\% CI for these differences frequently spanned zero or were trivial for most measures of strength and performance, inferring that the differences between classes may not always be clear and there could be considerable overlap, which is not desirable from a classification perspective (Hogarth et al., 2018).

To establish whether an alternative system could produce a more valid and subsequently fairer classification structure for proximal arm strength impairment than the existing IWRF system, cluster analyses were performed with both a 4- and 3-cluster structure. The 4-cluster structure effectively mirrors the number of classes used by the existing system and thus demonstrates an element of face validity. Clusters 1-3 represent decreasing severities of proximal arm strength impairment, akin to arm scores of 0.5 to 1.5 , with cluster 4 reflective of 'minimal to no proximal arm strength impairment'. Alternatively, within the 3-cluster structure, only 2 clusters (1 and 2) represent different severities of proximal arm strength impairment, with cluster 3 representative of 'minimal to no arm strength impairment'.

The 4-cluster structure produced a system whereby differences between adjacent classes were clearer for both strength and performance compared to the existing system, with moderate to very large differences in strength and performance now observed between clusters. The lower 95\% CI for these differences were also greater, with fewer differences in strength and performance classed as trivial. Nevertheless, such occurrences were still reported, which suggests that the potential for overlap in strength impairment and performance still exists between adjacent clusters. In addition to this, the 4-cluster structure was identified as being 'weak' according to the mean silhouette coefficients. 
Alternatively, when using a 3-cluster structure, differences between adjacent classes appeared clearer than 4 group alternatives. The moderate to very large differences in strength and moderate to large differences in performance observed for the 3-cluster structure were greater than what was previously observed for the existing IWRF system and similar to the 4cluster structure. However more importantly, the lower 95\% CI never spanned into trivial differences for strength or performance between adjacent clusters in the 3-cluster structure, and thus the likelihood for overlap between classes would be minimised using this method of classification. The value of a 3-cluster structure was further reinforced by the mean silhouette coefficients, which were stronger ('reasonable structure') than the 4-cluster structure. Therefore, given that a 3-cluster structure produced clearer differences in strength and performance between classes without increasing the intraclass variability $(\% \mathrm{CV})$ for either measure in fewer classes, would suggest that this structure would appear more valid and equitable for classifying arm strength impairment in WR.

Although the 3-cluster structure would appear a bigger change to the existing system and could be deemed more complex than the 4-cluster structure, due to the apparent loss of a class for quantifying proximal arm strength impairment, the 3-cluster structure actually brought about fewer changes. Aside from the change in the number of classes, outside of this only $19 \%$ $(10 / 53)$ athletes were assigned to a cluster that was not the numerical equivalent of their existing IWRF class. This is in line with the $18 \%$ change observed by a similar analysis within wheelchair racing (Connick et al., 2018b), although far less than the 40\% (21/53) athletes who changed class according to the 4-cluster structure. Perhaps the biggest concern with the 4cluster structure was not the number of athletes who were assigned an alternative cluster to the class they were originally allocated, it was the fact that two athletes were assigned to a cluster (2), two below their existing class (2.0). Such changes may be perceived as a lack of validity 
by key stakeholders, which is a significant threat to Paralympic sport (Tweedy et al., 2014), and subsequently further support for a 3-cluster structure could be achieved.

However, before the results of such a study can be implemented by an International Federation (IF), to potentially revise a sports classification system, there are a number of factors that must also be considered, many of which were outside the scope of the current study. The perceived impact that a revised system may have on athletes, coaches, classifiers, media and spectators must also be accounted for (Hogarth et al., 2018). A shift from manual muscle testing performed by classifiers to isometric strength testing performed by researchers, is likely to be the biggest change and logistical challenge for an IF to consider.

\section{$\underline{\text { Future recommendations and limitations }}$}

The current study has revealed that isometric strength tests and cluster analyses can be used to generate a valid system for the classification of proximal arm weakness in WR. However, a priority for future research will be to explore how these tests can be used to potentially allocate athletes a class based on these tests, which is a challenge for all para sports. For this to happen, further statistical enquiries are needed to identify where the thresholds between adjacent classes should lie. Secondly, decisions need to be made about whether a single test or multiple tests are needed to allocate class, which may also require further investigations. Further research must also consider the interaction between trunk and arm strength. The current study focussed entirely on athletes with no trunk function to better understand the effect of proximal arm weakness on performance in WR. Although relatively rare, athletes with a combination of arm and trunk strength impairment do exist in WR and it is important that research is extended to account for these individuals. An additional step towards the evidence-based classification of strength impaired WR players must then explore athletes with a distal arm weakness. For this 
to be achieved, further research is required to develop strength tests specific to these joints and muscles. Research will also be needed to develop tests capable of assessing ball handling skills, since this measure of performance will be most closely associated with a distal arm weakness, yet valid tests are currently lacking.

Further research must also investigate with the issue of gender with regards to strength impairment in WR since it is a mixed sport where males and females compete together. Although males and females are classified using the same tests in WR, a competition rule exists, whereby teams fielding a female are allowed an extra 0.5 in their line-up, which infers that females have 0.5 deducted from their original classification to account for their inferior strength compared to males (Mason et al., 2019). Subsequently a high priority for future research is the need to generate some evidence-based data surrounding this competition rule and to establish whether a 0.5 deduction is adequate across the whole classification spectrum to enable fair competition. Unfortunately, female participation in WR is still relatively low at the international level and hence why such a topic could not currently be explored, since only four females participated. However, progress in this area would be of benefit to any para sport where male and female athletes can compete together.

\section{Conclusions}

This study revealed that a series of single- and multi-joint isometric tests developed to assess the magnitude of proximal arm strength impairment were significantly related to mobility performance specific to WR and subsequently could be used for classification purposes. Cluster analyses of these strength measures revealed that two classes (3-cluster structure) may provide a stronger structure for classifying proximal arm strength impairment compared to the three 
383 federation, this information has the potential to act as a key step towards developing a 384 transparent, less contestable, evidence-based system for classifying proximal arm strength 385 impairment in WR athletes.

386

387 


\section{References}

389

390

391

392

393

394

395

396

397

398

399

400

401

402

403

404

405

406

407

408

409

410

Altmann VC, Groen BE, Groenen $\mathrm{KH}$ et al. Construct validity of the trunk impairment classification system in relation to objective measures of trunk impairment. Arch Phys Med Rehabil 2016; 97(3):437-444.

Altmann VC, Groen BE, Hart AL et al. The impact of trunk impairment on performancedetermining activities in wheelchair rugby. Scand J Med Sci Sports 2017; 27(9):1005-1014.

Altmann VC, Groen BE, Hart AL et al. Classifying trunk strength impairment according to the activity limitation caused in wheelchair rugby performance. Scand J Med Sci Sports 2018; 28(2):649-657.

Batterham AM, Hopkins, WG. Making meaningful inferences about magnitudes. Int J Sports Physiol Perform 2006; 1, 50-57.

Beckman EM, Connick MJ, Tweedy SM. Assessing muscle strength for the purpose of classification in Paralympic sport: a review and recommendations. J Sci Med Sport 2017; 20(4):391-396.

Connick MJ, Beckmann EM, Tweedy SM. Evolution and development of best practice in Paralympic classification. In: Brittain I, Beacom A, eds. Palgrave Handbook of Paralympic Studies. Palgrave Publishing Ltd, London, UK; 2018a:389-416.

Connick MJ, Beckman EM, Vanlandewijck YC et al. Cluster analysis of novel isometric strength measures produces a valid and evidence-based classification structure for wheelchair track athletics. Brit J Sports Med 2018b; 52(17):1123-1129.

Hinkle DE, Wiersma, W, Jurs SG. Applied Statistics for the Behavioural Sciences $5^{\text {th }}$ edition. 2003; Houghton Mifflin, Boston, Mass, USA. 
Hogarth L, Payton C, van de Vliet P et al. A novel guide to classification of para swimmers

413 Hogarth L, Nicholson V, Spathis J et al. A battery of strength tests for evidence-based 414 classification in Para swimming. J Sports Sci 2019; 37(4):404-413.

Dec 8]. Retrieved from http://www.paralympic.org/classification/2015-athlete-classification-

417 code.

International Wheelchair Rugby Federation. Classification manual $3^{\text {rd }}$ edition revised 2015.

Dec

$11]$.

Retrieved

from

http://www.iwrf.com/resources/iwrf_docs/IWRF_Classification_Manual_3rd_Edition_rev-

International Wheelchair Rugby Federation. Wheelchair rugby international rules. 2018.

Dec 10].

Retrieved

from

http://www.iwrf.com/resources/iwrf_docs/Wheelchair_Rugby_International_Rules_2019061

Kaufman L, Rousseeuw PJ. Finding Groups in Data: An Introduction to Cluster Analysis. 2005.

Mason BS, Porcellato L, van der Woude et al. A qualitative examination of wheelchair configuration for optimal mobility performance in wheelchair sports: a pilot study. J Rehabil Med 2010;42(2):141-149. evidence-based assessment of arm strength impairment in wheelchair rugby classification. $J$ Sci Med Sport 2019; Epub ahead of print. 
Mulroy SJ, Gronley JK, Newsam CJ et al. Electromyographic activity of shoulder muscles during wheelchair propulsion by paraplegic persons. Arch Phys Med Rehabil 1996; 77(2):187193.

437 Rousseeuw PJ. Silhouettes: a graphical aid to the interpretation and validation of cluster analysis. J Comput Appl Math 1987; 20:53-65.

Thorndike RL. Who belongs in the family? Psychometrika 1953; 18:267-276.

440 Tweedy SM. Taxonomic theory and the ICF: Foundations for a unified disability athletics classification. Adapt Phys Act Q 2002; 19(2):220-237.

Tweedy SM, Vanlandewijck YC. International Paralympic Committee position stand 443 background and scientific principles of classification in Paralympic sport. Brit J Sports Med $444 \quad 2011 ; 45: 259-269$.

445 Tweedy SM, Beckman EM, Connick MJ. Paralympic classification: conceptual basis, current 446 methods and research update. $P M \& R$ 2014; 6:S11-S17.

447 Tweedy SM, Mann D, Vandlandewijck YC. Research needs for the development of evidence448 based systems of classification for physical, vision, and intellectual impairments. In: 449 Vanlandewijck YC, Thomspon WR, eds. Training and Coaching the Paralympic Athlete. John 450 Wiley \& Sons, Hoboken, New Jersey, USA; 2016:122-149. 
Figure legends

453 Figure 1. Effect sizes $( \pm 95 \%$ CI $)$ demonstrating the magnitude of differences in strength 454 between adjacent classes for: a) existing IWRF system, b) 4-cluster structure and c) 3455 cluster structure. $\mathrm{Nb}$ in a) $1=\mathbf{0 . 5}, 2=\mathbf{1 . 0}, 3=\mathbf{1 . 5}$ and $4=\mathbf{2 . 0}$ arm scores.

456 Figure 2. Representation of class allocation and performance according to existing IWRF 457 system (a) and how individual athletes change according to 4-cluster structure (b) and 3458 cluster structure (c). Performance times are displayed for $\mathbf{2}$ m (left) and 10 m sprints 459 respectively (right).

460 Supplementary Figure. Illustration of the single-joint isometric strength tests for: a) 461 shoulder flexion, b) shoulder extension, c) elbow flexion, d) elbow extension and the multi462 joint strength tests: e) push, f) pull. 
A)
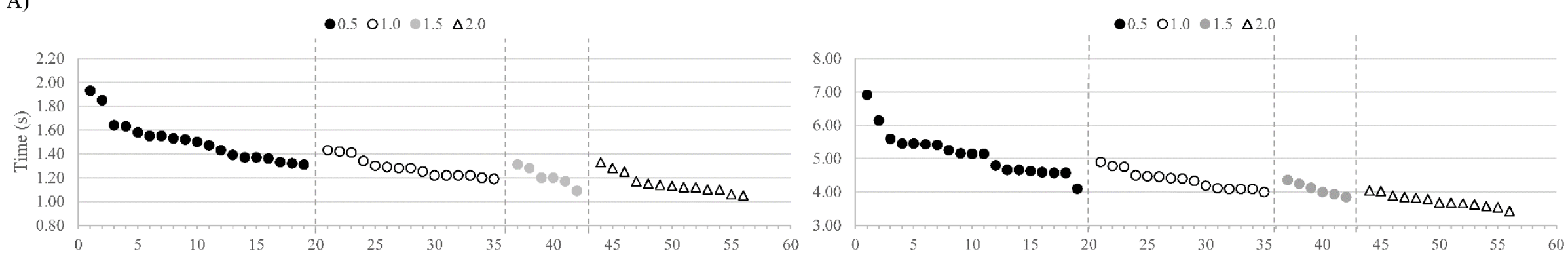

B)
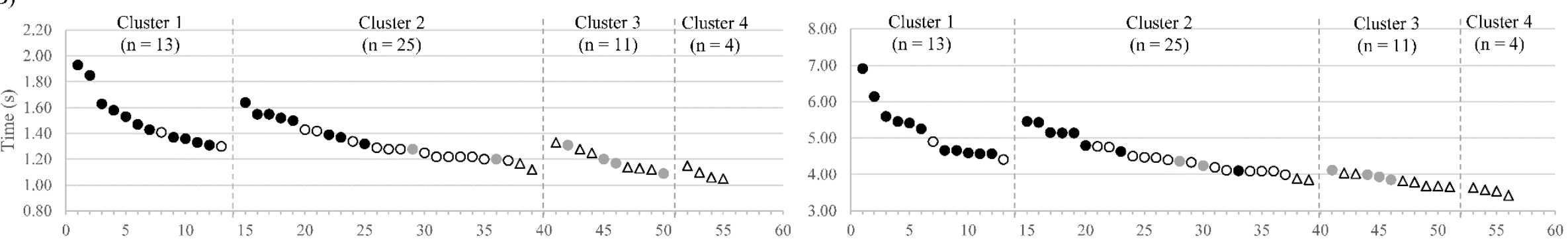

C)
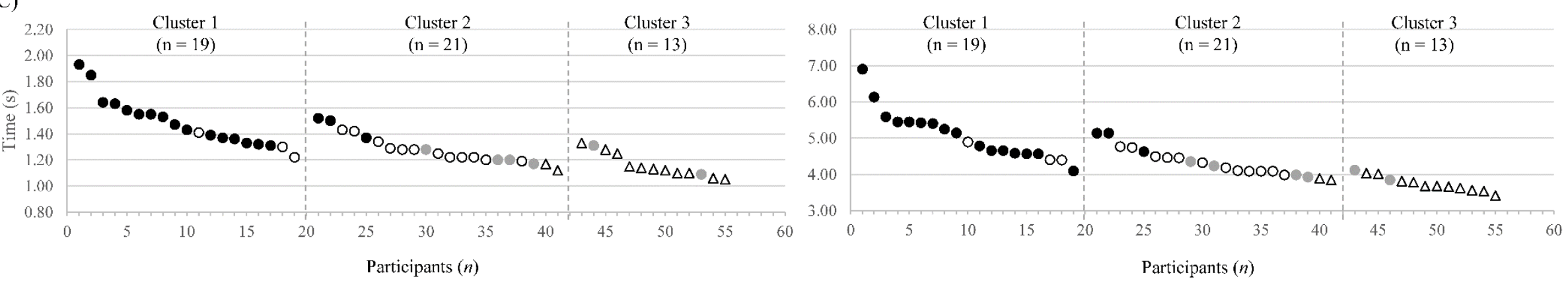
A)

Push

Pull

Shoulder Flexion D

Shoulder Flexion ND

Shoulder Extension D

Shoulder Extension ND

Elbow Flcxion D

Elbow Flexion ND

Elbow Extension D

Elbow Extension ND

B)

Push

Pull

Shoulder Flexion D

Shoulder Flexion ND

Shoulder Extension D

Shoulder Extension ND

Elbow Flexion D

Elbow Flexion ND

Elbow Extension D

Elbow Extension ND

C)

Push

Pull

Shoulder Flexion D

Shoulder Flexion ND

Shoulder Extension D

Shoulder Extension ND

Elbow Flexion D

Elbow Flexion ND

Elbow Extension D

Elbow Extension ND
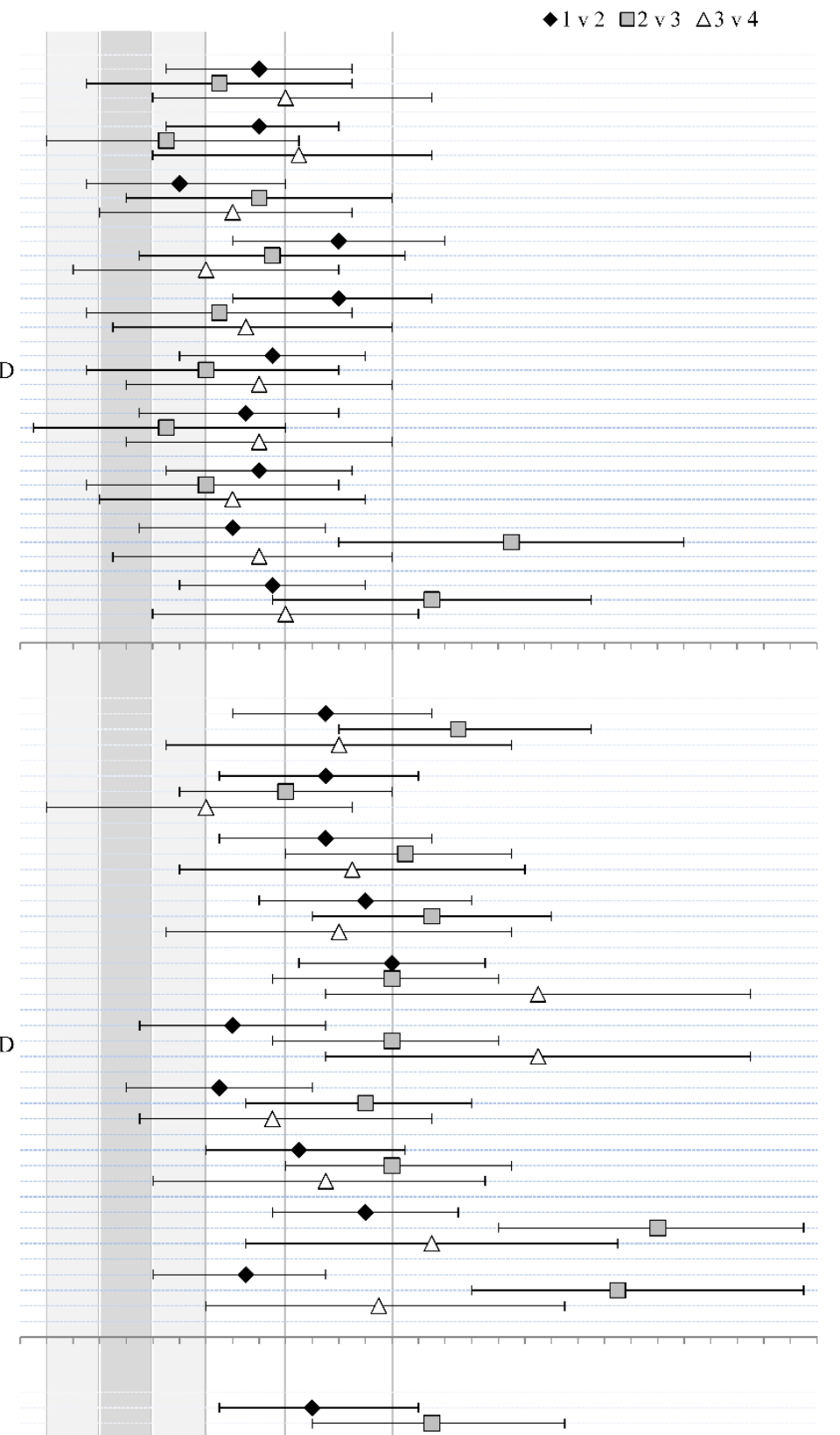

$\longrightarrow$

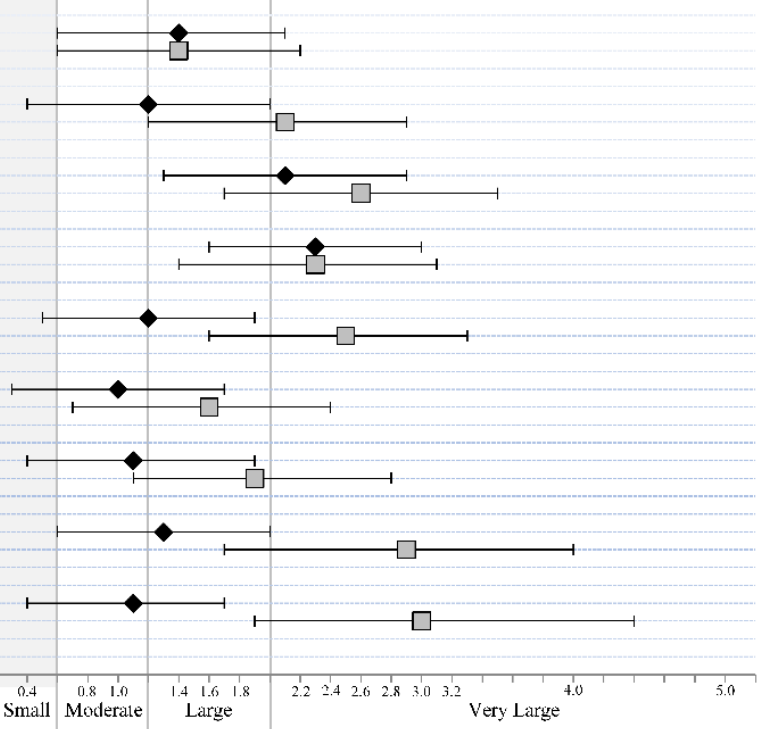

Effect sizes 
Table 1 Participants physical characteristics

\begin{tabular}{ll}
\hline Characteristic & Descriptive statistic \\
\hline Number (n) & $57(53$ male; 4 female $)$ \\
Age (years) & $33 \pm 7$ \\
Body mass (kg) & $72.1 \pm 10.0$ \\
Height (m) & $1.80 \pm 0.09$ \\
WR experience (years) & $11 \pm 6$ \\
Training volume (hours/week) & $10 \pm 5$ \\
SCI lesion level & $\mathrm{C} 5(n=20) ; \mathrm{C} 6(n=23) ; \mathrm{C} 7(n=14)$ \\
SCI completeness & Complete $(n=30) ;$ Incomplete $(n=27)$ \\
Existing IWRF arm score & $0.5(n=22) ; 1.0(n=16) ; 1.5(n=6) ; 2.0(n=13)$ \\
\hline
\end{tabular}


Table 2 Correlation coefficients $(95 \% \mathrm{CI})$ between isometric strength and performance measures in wheelchair rugby players $(n=57)$.

\begin{tabular}{|c|c|c|}
\hline \multirow[b]{3}{*}{ Strength } & & 472 \\
\hline & \multicolumn{2}{|c|}{ Performance } \\
\hline & $2 \mathrm{~m}$ times & $10 \mathrm{~m}$ times \\
\hline Push & $-0.64 *(-0.46,-0.77)$ & $-0.75^{*}(-0.61,-0.85) 474$ \\
\hline Pull & $-0.43 *(-0.19,-0.62)$ & $-0.55 *(-0.34,0.71) 475$ \\
\hline Shoulder flexion D & $-0.69 *(-0.52,-0.81)$ & $-0.82 *(-0.71,-0.89) 476$ \\
\hline Shoulder flexion ND & $-0.67 *(-0.50,-0.79)$ & $-0.82 *(-0.71,-0.89){ }_{477}$ \\
\hline Shoulder extension D & $-0.67 *(-0.50,-0.79)$ & $-0.66^{*}(-0.48,-0.79)$ \\
\hline Shoulder extension ND & $-0.63 *(-0.44,-0.76)$ & $-0.72 *(-0.57,-0.83)$ \\
\hline Elbow flexion D & $-0.60 *(-0.40,-0.74)$ & $-0.63 *(-0.44,-0.76)^{479}$ \\
\hline Elbow flexion ND & $-0.64 *(-0.46,-0.77)$ & $-0.68^{*}(-0.51,-0.80)^{480}$ \\
\hline Elbow extension D & $-0.76 *(-0.62,-0.85)$ & $-0.79 *(-0.67,-0.87)^{481}$ \\
\hline Elbow extension ND & $-0.77 *(-0.64,-0.86)$ & $-0.79 *(-0.67,-0.87)^{482}$ \\
\hline
\end{tabular}


Table 3 Mean (SD) isometric strength values (N) according to current IWRF classes and alternative classes proposed by the cluster analysis $(n=53)$. Range of intraclass variation represented by $\mathrm{CV}(\%)$

\begin{tabular}{|c|c|c|c|c|c|c|c|c|c|c|}
\hline \multirow[t]{2}{*}{ Cluster / class structure } & \multirow[t]{2}{*}{ Push } & \multirow[t]{2}{*}{ Pull } & \multicolumn{2}{|c|}{ Shoulder Flexion } & \multicolumn{2}{|c|}{ Shoulder Extension } & \multicolumn{2}{|c|}{ Elbow Flexion } & \multicolumn{2}{|c|}{ Elbow Extension } \\
\hline & & & Dom & ND & Dom & ND & Dom & ND & Dom & ND \\
\hline \multicolumn{11}{|l|}{ Current IWRF classes } \\
\hline $0.5(\mathrm{n}=19)$ & $\begin{array}{l}243.5 \\
(69.3)\end{array}$ & $\begin{array}{l}266.5 \\
(70.3)\end{array}$ & $\begin{array}{l}163.8 \\
(37.6)\end{array}$ & $\begin{array}{l}144.0 \\
(33.0)\end{array}$ & $\begin{array}{l}117.8 \\
(28.7)\end{array}$ & $\begin{array}{l}106.3 \\
(23.2)\end{array}$ & $\begin{array}{l}191.1 \\
(41.2)\end{array}$ & $\begin{array}{l}160.2 \\
(41.7)\end{array}$ & $\begin{array}{l}15.0 \\
(7.5)\end{array}$ & $\begin{array}{c}9.9 \\
(4.2)\end{array}$ \\
\hline $1.0(\mathrm{n}=15)$ & $\begin{array}{l}311.9 \\
(63.9)\end{array}$ & $\begin{array}{l}294.9 \\
(87.5)\end{array}$ & $\begin{array}{l}238.3 \\
(54.7)\end{array}$ & $\begin{array}{l}210.6 \\
(50.3)\end{array}$ & $\begin{array}{l}159.2 \\
(49.7)\end{array}$ & $\begin{array}{l}132.6 \\
(35.7)\end{array}$ & $\begin{array}{l}231.0 \\
(42.3)\end{array}$ & $\begin{array}{l}192.6 \\
(36.0)\end{array}$ & $\begin{array}{c}30.9 \\
(20.7)\end{array}$ & $\begin{array}{c}21.2 \\
(19.8)\end{array}$ \\
\hline $1.5(\mathrm{n}=6)$ & $\begin{array}{l}364.9 \\
(97.9)\end{array}$ & $\begin{array}{l}319.0 \\
(50.3)\end{array}$ & $\begin{array}{l}301.2 \\
(73.8)\end{array}$ & $\begin{array}{l}272.7 \\
(76.6)\end{array}$ & $\begin{array}{l}197.7 \\
(62.9)\end{array}$ & $\begin{array}{l}159.5 \\
(57.4)\end{array}$ & $\begin{array}{l}244.2 \\
(65.9)\end{array}$ & $\begin{array}{l}220.3 \\
(59.2)\end{array}$ & $\begin{array}{l}124.6 \\
(51.7)\end{array}$ & $\begin{array}{c}83.6 \\
(40.9)\end{array}$ \\
\hline $2.0(\mathrm{n}=13)$ & $\begin{array}{c}507.7 \\
(123.2)\end{array}$ & $\begin{array}{l}407.2 \\
(76.4)\end{array}$ & $\begin{array}{l}361.8 \\
(80.7)\end{array}$ & $\begin{array}{l}324.0 \\
(82.9)\end{array}$ & $\begin{array}{l}259.5 \\
(66.5)\end{array}$ & $\begin{array}{l}225.4 \\
(66.8)\end{array}$ & $\begin{array}{l}301.1 \\
(54.2)\end{array}$ & $\begin{array}{l}267.4 \\
(59.2)\end{array}$ & $\begin{array}{l}181.5 \\
(61.4)\end{array}$ & $\begin{array}{l}155.0 \\
(65.8)\end{array}$ \\
\hline $\mathrm{CV}(\%)$ & $21-29$ & $16-30$ & $22-25$ & $23-28$ & $24-32$ & $22-36$ & $18-27$ & $19-27$ & $34-67$ & $42-93$ \\
\hline \multicolumn{11}{|l|}{ 4-cluster structure } \\
\hline $1(\mathrm{n}=13)$ & $\begin{array}{l}216.5 \\
(70.8)\end{array}$ & $\begin{array}{l}220.1 \\
(46.6)\end{array}$ & $\begin{array}{l}145.0 \\
(30.5)\end{array}$ & $\begin{array}{l}127.6 \\
(25.5)\end{array}$ & $\begin{array}{l}117.4 \\
(29.9)\end{array}$ & $\begin{array}{l}103.8 \\
(23.5)\end{array}$ & $\begin{array}{l}174.5 \\
(37.5)\end{array}$ & $\begin{array}{l}136.8 \\
(23.6)\end{array}$ & $\begin{array}{l}14.3 \\
(8.7)\end{array}$ & $\begin{array}{l}10.2 \\
(4.5)\end{array}$ \\
\hline $2(\mathrm{n}=25)$ & $\begin{array}{l}305.8 \\
(51.0)\end{array}$ & $\begin{array}{l}311.8 \\
(67.8)\end{array}$ & $\begin{array}{l}232.5 \\
(55.1)\end{array}$ & $\begin{array}{l}201.4 \\
(41.3)\end{array}$ & $\begin{array}{l}149.0 \\
(46.3)\end{array}$ & $\begin{array}{l}126.4 \\
(35.5)\end{array}$ & $\begin{array}{l}224.2 \\
(38.8)\end{array}$ & $\begin{array}{l}194.9 \\
(35.0)\end{array}$ & $\begin{array}{c}36.1 \\
(30.4)\end{array}$ & $\begin{array}{c}23.2 \\
(24.1)\end{array}$ \\
\hline $3(\mathrm{n}=11)$ & $\begin{array}{l}471.5 \\
(91.3)\end{array}$ & $\begin{array}{l}391.7 \\
(62.4)\end{array}$ & $\begin{array}{l}344.2 \\
(50.9)\end{array}$ & $\begin{array}{l}312.6 \\
(60.0)\end{array}$ & $\begin{array}{l}234.1 \\
(36.5)\end{array}$ & $\begin{array}{l}197.5 \\
(38.5)\end{array}$ & $\begin{array}{l}295.4 \\
(44.0)\end{array}$ & $\begin{array}{l}260.9 \\
(26.7)\end{array}$ & $\begin{array}{l}162.7 \\
(35.3)\end{array}$ & $\begin{array}{l}131.6 \\
(39.9)\end{array}$ \\
\hline $4(n=4)$ & $\begin{array}{l}611.7 \\
(65.9)\end{array}$ & $\begin{array}{l}432.7 \\
(95.5)\end{array}$ & $\begin{array}{l}428.7 \\
(49.5)\end{array}$ & $\begin{array}{l}402.5 \\
(34.9)\end{array}$ & $\begin{array}{l}339.9 \\
(21.7)\end{array}$ & $\begin{array}{l}303.6 \\
(13.0)\end{array}$ & $\begin{array}{l}338.8 \\
(12.7)\end{array}$ & $\begin{array}{l}302.8 \\
(35.0)\end{array}$ & $\begin{array}{l}244.6 \\
(37.9)\end{array}$ & $\begin{array}{l}214.9 \\
(52.6)\end{array}$ \\
\hline CV $(\%)$ & $11-33$ & $16-22$ & $12-24$ & $9-21$ & $6-31$ & $4-28$ & $4-22$ & $10-18$ & $16-84$ & $25-103$ \\
\hline \multicolumn{11}{|l|}{ 3-cluster structure } \\
\hline $1(\mathrm{n}=19)$ & $\begin{array}{l}234.6 \\
(66.3)\end{array}$ & $\begin{array}{l}242.6 \\
(53.1)\end{array}$ & $\begin{array}{l}157.2 \\
(34.6)\end{array}$ & $\begin{array}{l}139.0 \\
(28.9)\end{array}$ & $\begin{array}{l}117.6 \\
(28.5)\end{array}$ & $\begin{array}{l}103.9 \\
(24.5)\end{array}$ & $\begin{array}{l}187.4 \\
(40.4)\end{array}$ & $\begin{array}{l}154.0 \\
(38.4)\end{array}$ & $\begin{array}{l}14.8 \\
(8.6)\end{array}$ & $\begin{array}{c}9.9 \\
(4.6)\end{array}$ \\
\hline $2(n=21)$ & $\begin{array}{l}327.5 \\
(67.7)\end{array}$ & $\begin{array}{l}318.2 \\
(72.9)\end{array}$ & $\begin{array}{l}253.9 \\
(53.4)\end{array}$ & $\begin{array}{l}217.4 \\
(39.4)\end{array}$ & $\begin{array}{l}162.0 \\
(46.1)\end{array}$ & $\begin{array}{l}134.2 \\
(33.3)\end{array}$ & $\begin{array}{l}234.1 \\
(44.9)\end{array}$ & $\begin{array}{l}202.6 \\
(39.0)\end{array}$ & $\begin{array}{c}52.5 \\
(45.4)\end{array}$ & $\begin{array}{c}33.9 \\
(31.6)\end{array}$ \\
\hline $3(n=13)$ & $\begin{array}{c}519.8 \\
(102.7)\end{array}$ & $\begin{array}{l}415.6 \\
(65.7)\end{array}$ & $\begin{array}{l}375.4 \\
(62.5)\end{array}$ & $\begin{array}{l}349.0 \\
(63.5)\end{array}$ & $\begin{array}{l}273.1 \\
(54.4)\end{array}$ & $\begin{array}{l}238.8 \\
(51.5)\end{array}$ & $\begin{array}{l}307.6 \\
(46.0)\end{array}$ & $\begin{array}{l}273.1 \\
(36.3)\end{array}$ & $\begin{array}{l}190.1 \\
(50.8)\end{array}$ & $\begin{array}{l}163.2 \\
(57.4)\end{array}$ \\
\hline
\end{tabular}


Table 4 Differences in performance across current IWRF classes for arm strength impairment and alternative classes based on isometric strength

\begin{tabular}{|c|c|c|c|c|c|c|c|}
\hline \multirow[b]{2}{*}{ Class structure } & \multirow[b]{2}{*}{ Cluster / class } & \multicolumn{3}{|c|}{2 m sprint times (s) } & \multicolumn{3}{|c|}{$10 \mathrm{~m}$ sprint times $(\mathrm{s})$} \\
\hline & & Mean (SD) & $\mathrm{ES}(95 \% \mathrm{CI})$ & CV (\%) & Mean (SD) & $\mathrm{ES}(95 \% \mathrm{CI})$ & CV (\%) \\
\hline \multirow[t]{4}{*}{ Current IWRF classes } & $0.5(\mathrm{n}=19)$ & $1.51(0.17)$ & $1.7(0.9,2.5)$ & 11.3 & $5.14(0.65)$ & $1.5(0.7,2.2)$ & 12.6 \\
\hline & $1.0(\mathrm{n}=15)$ & $1.28(0.08)$ & $0.9(-0.1,1.9)$ & 6.3 & $4.37(0.28)$ & $1.1(0.1,2.1)$ & 6.4 \\
\hline & $1.5(\mathrm{n}=6)$ & $1.21(0.08)$ & $0.8(-0.2,1.7)$ & 6.6 & $4.08(0.19)$ & $1.9(0.7,3.0)$ & 4.7 \\
\hline & $2.0(\mathrm{n}=13)$ & $1.15(0.08)$ & $\mathrm{n} / \mathrm{a}$ & 7.0 & $3.74(0.18)$ & $\mathrm{n} / \mathrm{a}$ & 4.8 \\
\hline \multirow[t]{4}{*}{ 4-cluster structure } & $1(n=13)$ & $1.50(0.20)$ & $1.1(0.4,1.8)$ & 13.3 & $5.16(0.74)$ & $1.2(0.4,1.9)$ & 14.3 \\
\hline & $2(\mathrm{n}=25)$ & $1.33(0.14)$ & $1.1(0.3,1.9)$ & 10.5 & $4.50(0.47)$ & $1.6(0.8,2.4)$ & 10.4 \\
\hline & $3(\mathrm{n}=11)$ & $1.19(0.09)$ & $1.2(0.0,2.4)$ & 7.6 & $3.87(0.16)$ & $2.2(0.8,3.6)$ & 4.1 \\
\hline & $4(n=4)$ & $1.09(0.05)$ & $\mathrm{n} / \mathrm{a}$ & 4.6 & $3.54(0.09)$ & $\mathrm{n} / \mathrm{a}$ & 2.5 \\
\hline \multirow[t]{3}{*}{ 3-cluster structure } & $1(\mathrm{n}=19)$ & $1.48(0.19)$ & $1.3(0.6,2.0)$ & 12.8 & $5.08(0.68)$ & $1.4(0.7,2.1)$ & 13.4 \\
\hline & $2(\mathrm{n}=21)$ & $1.28(0.11)$ & $1.1(0.4,1.9)$ & 8.6 & $4.33(0.38)$ & $1.7(0.9,2.6)$ & 8.8 \\
\hline & $3(\mathrm{n}=13)$ & $1.16(0.10)$ & $\mathrm{n} / \mathrm{a}$ & 8.6 & $3.76(0.21)$ & $\mathrm{n} / \mathrm{a}$ & 5.6 \\
\hline
\end{tabular}

